\title{
THE INFLUENCE OF 3D VIRTUAL SCENERIES ON ABILITY TO MAINTAIN BALANCE
}

\author{
J. Jurkojć*, P. Wodarski* ${ }^{* *}$ R. Michnik*** A. Bieniek ${ }^{\dagger}$, C. Herrera Ligero ${ }^{\star}$, E. Pavan $^{\star *}$
}

\begin{abstract}
The aim of the study was to assess the influence of virtual environment on ability to maintain balance in comparison with tests conducted with eyes open and closed. Measurements were carried out on a group of 27 participants. FDM-S Zebris platform was used to determine center of pressure positions and Oculus Rift to present virtual sceneries. Analysis of results was conducted both in time and frequency domain. Obtained results made it possible to obsefve similatities between measurements with eyes closed and in virtual environment.
\end{abstract}

Keywords: measurements of ability to maintain balance, frequency domain analysis, FFT

\section{Introduction}

The use of virtual environment in measurements of ability to maintain balance are getting more and more popular. The estimation of the influence of virtual sceneries on stabilographic quantities was a research subject of many scientists. Alahmari et al. (2014) and Horlings et al. (2009) studied differences between results obtained during standing on unstable basis in virtual scenery showing the influence of virtual environment. Cleworth et al. (2016) modelled a room in two variants: with a floor in front of a tested person and without a floor - participant could see another room below. Scientists studied behaviour of participants in these surroundings, drawing conclusions that measurements of this kind can be used as a tool to diagnose balance disturbances. Michnik et al.(2014, 2016, 2017) and Jurkojć et al.(2017, 2018) tested the influence of oscillating virtual scenery or movement of virtual objects on human balance using both standard analysis in time domain as well as analyses in frequency domain using Fast Fourier Transform. The greatest advantage of such tests is that the use of virtual reality technology can "transfer" a person to any surroundings (Bartnicka, 2014). But it seems that even the best graphical quality of elaborated scenery does not give a full sense of security in terms of natural moving or maintaining balance. Permanent lack of knowledge of real surroundings and potential dangers can cause, that human behaviour can be different from that in real environment. Therefore the use of virtual reality systems in medical diagnosis must be preceded by experiments enabling determination of influence of such systems both on healthy and ill people as well as how this influence can be changed by changing parameters of virtual scenery. This research can be done both by means of experimental and modelling methods (Michnik, 2014 and Jurkojć, 2009)

The aim of this study was do determine how the immobile, virtual scenery can change human behaviour during stabilographic measurements. Results of analyses can be used in elaboration of rehabilitation process

\footnotetext{
Jacek Jurkojc PhD. Eng: Department of Biomechatronics, Faculty of Biomedical Engeenering, Silesian Univesity of Technology; Poland, Jacek.Jurkojc@polsl.pl

** Piotr Wodarski PhD. Eng: Department of Biomechatronics, Faculty of Biomedical Engeenering, Silesian Univesity of Technology; Poland, Piotr.Wodarski@polsl.pl

*** Robert Michnik, PhD. DSc. Eng.: Department of Biomechatronics, Faculty of Biomedical Engeenering, Silesian Univesity of Technology; Poland, Robert.Michnik@polsl.pl

$\dagger \quad$ Andrzej Bieniek MSc. Eng: Department of Biomechatronics, Faculty of Biomedical Engeenering, Silesian Univesity of Technology; Poland, Andrzej.Bieniek@polsl.pl

* Cristina Herrera Ligero MD: Instituto de Biomecánica de Valencia; Spain, cristina.herrera@ibv.upv.es

\# Esteban Pavan, PhD: Laboratory of Biomedical Technologies Politecnico Milano, Italy, esteban.pavan@polimi.it
} 
based on the use of virtual reality technologies destined for people with neurological diseases e.g. people after stroke.

\section{Methods}

All measurements and calculations were conducted in Biomechatronics Department laboratories, Faculty of Biomedical Engineering, Silesian University of Technology and were previously approved by the Ethics in Research Committee of the Academy of Physical Education in Katowice (protocol number 11/2015).

\subsection{Participants}

A group of 27 participants (13 females and 14 males) of a mean weight $67.5 \mathrm{~kg}$ (SD 12.0), a mean height $173.6 \mathrm{~cm}$ (SD 8.8) and a mean age 22.0 years (SD 1.3) took part in measurements. All selected participants were healthy, had no problems with balance maintaining and were not obese (mean BMI 22.2, SD2.7, value less than 30 for each person).

\subsection{Measurement position}

All measurements of center of pressure (COP) positions were conducted with the use of Zebris FDM-S platform. Platform's software enables export of subsequent COP coordinates.

The 3D projection of scenery was carried out by means of the Oculus Rift system. There were two sceneries. The first one was designed as a furnished room with objects visible in a distance less than 3meters (named closed scenery), whereas the second presented open space desert (named open scenery). Both sceneries were prepared in the Unity environment.

\subsection{Method of measurements and analysis}

There were three measurements conducted for each participant:

- real environment, eyes open

- real environment, eyes closed

- virtual environment.

In virtual environment half of the group was exposed to the closed scenery and half to the open scenery. Each measurement lasted 50 seconds, but only 30 seconds from the middle of the recorded data were analyzed. Obtained COP positions were used to calculate quantities in time domain: mean velocity of COP, ellipse area containing 95\% COP positions and mean COP velocity in sagittal plane (AP direction).Mean velocity for each participant was calculated as a ratio between length of the COP path and time of measurement (analyzed period). Analyses were based on medians due to the lack of normal decomposition. Additionally analysis of curves of Fast Fourier Transform (FFT) were conducted. These curves were obtained for successive positions of COP in AP direction..In order to check if differences between individual measurements conditions (eyes open, eyes closed and virtual environment) are statistically significant Wilcoxon test for dependent groups and U Mann Whitney test for independent groups were conducted.

\section{Results}

Figure1 shows the medians with quartiles and ranges of obtained measurement results with open and closed eyes as well as in a virtual environment. The exact median values are presented in table 1, whereas table 2 shows coefficients indicating whether the differences between the individual measurements were statistically significant. FFT curves obtained for all measurements are presented in fig. 2.

Tab. 1 Median values of mean COP velocity, mean velocity in AP direction, ellipse area. eo - eyes open, ec-eyes closed, Oc_n-virtual environment

\begin{tabular}{cccc}
\hline & $\begin{array}{c}\text { Mean COP } \\
\text { velocity }[\mathbf{m m} / \mathbf{s}]\end{array}$ & $\begin{array}{c}\text { Mean COP } \\
\text { velocity in AP } \\
\text { direction }[\mathbf{m m} / \mathbf{s}]\end{array}$ & $\begin{array}{c}\text { Ellipse area } \\
{\left[\mathbf{m m}^{\mathbf{2}}\right]}\end{array}$ \\
\hline eo & 7,6 & 4,6 & 112,9 \\
\hline ec & 9,0 & 5,8 & 98,8 \\
\hline Oc_n & 8,2 & 5,3 & 127,6 \\
\hline
\end{tabular}




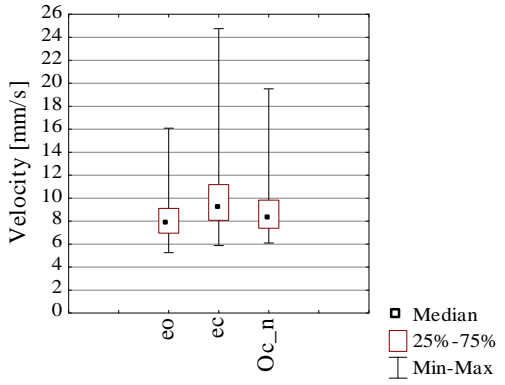

a)

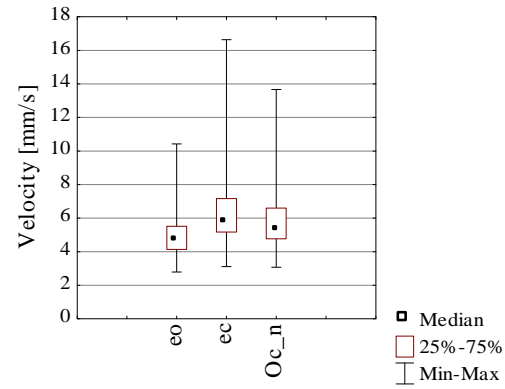

b)

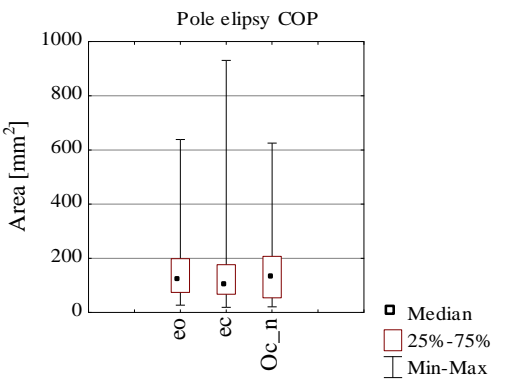

c)

Fig. 1 Median values, 25\% - 75\% quartyl as well as maximum and minimum value of: a) mean COP velocity, b) mean velocity in AP direction, c) ellipse area. eo - eyes open, ec-eyes closed, Oc_ $n-v i r t u a l$ environment

Tab. 2 p values of Wilcoxon test and U Mann Whitney test defining statistically sagnificant differences between tests. $p>0.05$ - no statistically significant differences. eo-eyes open, ec - eyes closed, Oc_n-virtual environment

\begin{tabular}{ccccccc}
\hline & \multicolumn{2}{c}{ Mean COP velocity } & \multicolumn{2}{c}{$\begin{array}{c}\text { Mean COP velocity } \\
\text { in AP direction }\end{array}$} & \multicolumn{2}{c}{ Ellipse area } \\
\hline $\begin{array}{c}\text { Compared } \\
\text { sceneries }\end{array}$ & W test & $\begin{array}{c}\text { UM-W } \\
\text { test }\end{array}$ & W test & $\begin{array}{c}\text { UM-W } \\
\text { test }\end{array}$ & W test & $\begin{array}{c}\text { UM-W } \\
\text { test }\end{array}$ \\
\hline eo-ec & 0,000000 & - & 0,000000 & - & 0,084668 & - \\
\hline eo - Oc_n & - & 0,030924 & - & 0,002796 & - & 0,777450 \\
\hline ec - Oc_n & - & 0,075242 & - & 0,084387 & - & 0,629695
\end{tabular}

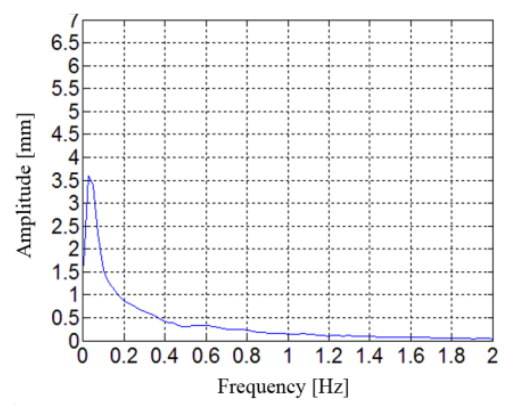

a)

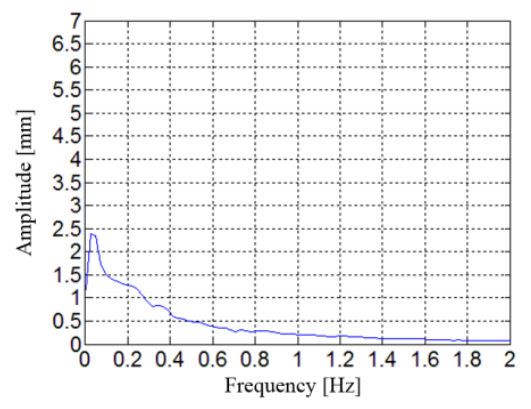

b)

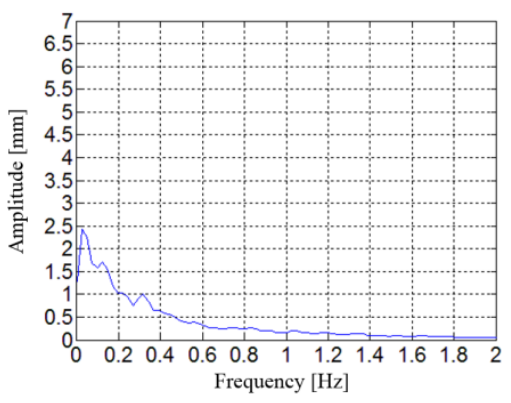

c)

Fig. 2 FFT curves obtained for a) eyes open, b) eyes closed and c) virtual environment

\section{Discussion and conclusions}

In all cases - except ellipse area - the highest values were obtained for the measurement with eyes closed, whereas the lowest with eyes open. However statistically significant differences were obtained in comparisons: 
- between tests with eyes open and closed

- between tests with eyes open and tests in virtual scenery

These results suggest that the influence of virtual environment is similar to measurements realised with eyes closed. It means, that even good simulation presenting virtual sceneries corresponding to real world is not able to make tested participants feel safely enough to behave like in real environment. These results can be confirmed by FFT curves analysis. One can notice the increased values of the FFT function in the frequency range between $0.1 \mathrm{~Hz}$ to $0.6 \mathrm{~Hz}$ both for eyes closed and virtual environment when compared to the same region of the curve obtained for the eyes open test. This indicates that there are probably peaks on curves obtained for individual participants, which are visible, after averaging, as a region with higher values on the curve. These increased values not only suggest that the influence of closed eyes and virtual environment is similar, but also show frequencies of appearing cyclic components.

It is also worth noting that there were no statistically significant differences between any of the tests in the case of the COP ellipse area. It means, that growth of COP velocities in cases with eyes closed and virtual sceneries were related to faster movements performed in the same area - range of COP movement was more or less the same.

\section{Acknowledgments.}

This work has been done under the project "Development of Innovative Training Contents Based on the Applicability of Virtual Reality in the Field of Stroke Rehabilitation", contract number: 2017-1-PL01KA202-038370. This project has been funded with support from the European Commission, Program Erasmus+. This communication reflects the views only of the authors, and the Commission cannot be held responsible for any use which may be made of the information contained therein.

\section{References}

Alahmari K.A., Marchetti G.F., Sparto P.J., Furman J.M., Whitney S.L. (2014) Estimating postural control with the balance rehabilitation unit: measurement consistency, accuracy, validity, and comparison with dynamic posturography. Archives of Physical Medicine and Rehabilitation, 95, pp. 65-73

Bartnicka J., Winkler T. (2014) Virtualization of Hospital Processes in Forming the Knowledge-Based Organization, in: Human factors of a global society. A system of systems perspective. CRC Press/Taylor \& Francis Group, pp. 211-218

Cleworth T.W., Chua R., Inglis T., Carpenter M.G. (2016) Influence of virtual height exposure on postural reactions to support surface translations. Gait\&Posture, 47, pp. 96-102

Horlings C.G.C., Carpenter M.G., Küng U.M., Honegger F., Wiederhold B., Allum J.H.J. (2009) Influence of virtual reality on postural stability during movements of quiet stance. Neuroscience Letters, 451, pp. 227-231

Jurkojć J. (2018) Balance disturbances coefficient as a new value to assess ability to maintain balance on the basis of FFT curves. Acta of Bioengineering and Biomechanics, 20 (1) article in press, DOI: 10.5277/ABB-01082-201802

Jurkjć J., Michnik R., Pauk J. (2009) Identification of muscle forces acting in lower limbs with the use of planar and spatial mathematical model. Journal of Vibroengineering, 11 (3), pp. 566-570

Jurkojć J., Wodarski P., Bieniek A., Gzik M., Michnik R. (2017) Influence of changing frequency and various sceneries on stabilometric parameters and on the effect of adaptation in an immersive $3 \mathrm{D}$ virtual environment. Acta of Bioengineering and Biomechanics, 19 (3), pp. 129-137

Michnik R., Jurkojć J., Wodarski P., Gzik M., Bieniek A. (2014) The influence of the scenery and the amplitude of visual disturbances in the virtual reality on the maintaining the balance, Archives of Budo, 10, pp. $133-140$

Michnik R., Jurkojć J., Wodarski P., Gzik M., Jochymczyk-Woźniak K., Bieniek A. (2016) The influence of frequency of visual disorders on stabilographic parameters. Acta of Bioengineering and Biomechanics, 18 (1), pp. 25-33

Michnik R., Wodarski P., Bieniek A., Jurkojć J., Mosler D., Kalina R.M. (2017) Effectiveness of avoiding collision with an object in motion - virtual reality technology in diagnostic and training from perspective of prophylactic of body injuries. Archives of Budo,13, pp. 203-210

Tossavainen T., Juhola M., Pyykko I., Aalto H., Toppila E. (2003) Development of virtual reality stimuli for force platform posturography. International Journal of Medical Informatics.70, pp. 277-283 